\title{
Association between anxiety and hypertension: a systematic review and meta-analysis of epidemiological studies
}

This article was published in the following Dove Press journal:

Neuropsychiatric Disease and Treatment

22 April 2015

Number of times this article has been viewed

\author{
Yu Pan ${ }^{1,2, *}$ \\ Wenpeng Cail,* \\ Qi Cheng ${ }^{3, *}$ \\ Wei Dong' \\ Ting $\mathrm{An}^{4}$ \\ Jin Yan'
}

'Department of Psychology and Mental Health, Second Military Medical University, Shanghai,

2Department of Psychology, Peoples Liberation Army General Hospital, Beijing, ${ }^{3}$ Department of Child and Adolescent Behavioral Medicine, The 102 Hospital of PLA, Changzhou, ${ }^{4}$ Department of Internal Medicine, The PLA Second Artillery

Force General Hospital, Beijing,

People's Republic of China

*These authors contributed equally to this work
Correspondence: Jin Yan

Department of Psychology and Mental Health, Second Military Medical University, 800 Xiangyin Road, Shanghai, 200433, People's Republic of China

Tel +86I3661665500

Email yanjingk@qq.com
Background: Epidemiological studies have repeatedly investigated the association between anxiety and hypertension. However, the results have been inconsistent. This study aimed to summarize the current evidence from cross-sectional and prospective studies that evaluated this association.

Methods: Seven common databases were searched for articles published up to November 2014 Cross-sectional and prospective studies that reported an association between the two conditions in adults were included. Data on prevalence, incidence, unadjusted or adjusted odds ratios or hazard ratios, and 95\% confidence intervals (CIs) were extracted or calculated by the authors. The pooled odds ratio was calculated separately for cross-sectional and prospective studies using random-effects models. The $Q$ test and $I^{2}$ statistic was used to assess heterogeneity. A funnel plot and modified Egger linear regression test were used to estimate publication bias.

Results: The search yielded 13 cross-sectional studies ( $\mathrm{n}=151,389)$, and the final pooled odds ratio was $1.18\left(95 \% \mathrm{CI} 1.02-1.37 ; P_{\mathrm{Q}}<0.001 ; I^{2}=84.9 \%\right)$. Eight prospective studies with a total sample size of 80,146 and 2,394 hypertension case subjects, and the pooled adjusted hazard ratio was 1.55 (95\% CI $\left.1.24-1.94 ; P_{\mathrm{Q}}<0.001 ; I^{2}=84.6 \%\right)$. The meta-regression showed that location, diagnostic criteria for anxiety, age, sex, sample size, year of publication, quality, and years of follow-up (for prospective study) were not sources of heterogeneity.

Conclusion: Our results suggest that there is an association between anxiety and increased risk of hypertension. These results support early detection and management of anxiety in hypertensive patients.

Keywords: human, epidemiological association, anxiety disorder, hypertension, meta-analysis

\section{Introduction}

Hypertension, one of the most common diseases worldwide, is estimated to affect one quarter of all adults, and has been identified as the leading cause of mortality and the third cause of disability-adjusted life years worldwide. ${ }^{1}$ According to a report by Kearney et al the total number of adults with hypertension in 2025 was predicted to increase to 1.56 billion worldwide. ${ }^{2}$ Identifying and characterizing modifiable risk factors of hypertension remain important for public health and clinical medicine.

Hypertension has a multifactorial etiology, where genetic as well as psychosocial and environmental factors appear to be of importance. ${ }^{3,4}$ However, there are complex physiological processes involved and the linkage among psychosocial factors and hypertension is not fully understood. ${ }^{5-7}$ Anxiety is one of the most common psychiatric illnesses in adults and is a major public health problem in many countries, ${ }^{8,9}$ damaging the affected individual's health and quality of life..$^{10}$ Because both hypertension and 
anxiety confer significant public health challenges, the association between the two conditions has recently attracted attention.

A number of epidemiological studies have been conducted to investigate this association, with inconsistent results reported. Some investigations show that anxiety is associated with hypertension, individuals with anxiety having a higher risk of hypertension than those without anxiety. ${ }^{11-14}$ Further, hypertension patients have a higher risk of anxiety than those without hypertension. ${ }^{15,16}$ However, some researchers do not support the role of anxiety symptoms in the development of hypertension. ${ }^{17,18}$ Some studies have even reported that anxiety is associated with a decrease in blood pressure. ${ }^{19,20}$ To date, there has not been a meta-analysis to explore the association between anxiety and hypertension. Therefore, we summarized the available data from cross-sectional and prospective studies, and performed meta-analyses to investigate the cross-sectional correlation and longitudinal relationship between anxiety and hypertension.

\section{Methods}

\section{Search strategy}

A comprehensive search, restricted to human studies published in the English or Chinese language, was performed using the following databases: PubMed, ISI Web of Science, EMBASE, PsycInfo, China National Knowledge Infrastructure, China Biology Medical literature database, and Database of Chinese Scientific and Technical Periodicals. The search terms ("anxiety" or "worry" or "post-traumatic stress" or "panic" or "agoraphobia" or "phobia" or "obsessive-compulsive") and ("hyperten*" or "high blood pressure") were used in various combinations for relevant articles without time restriction (Figure 1 shows details of the search process and study selection). The last search was performed on November 6, 2014. In

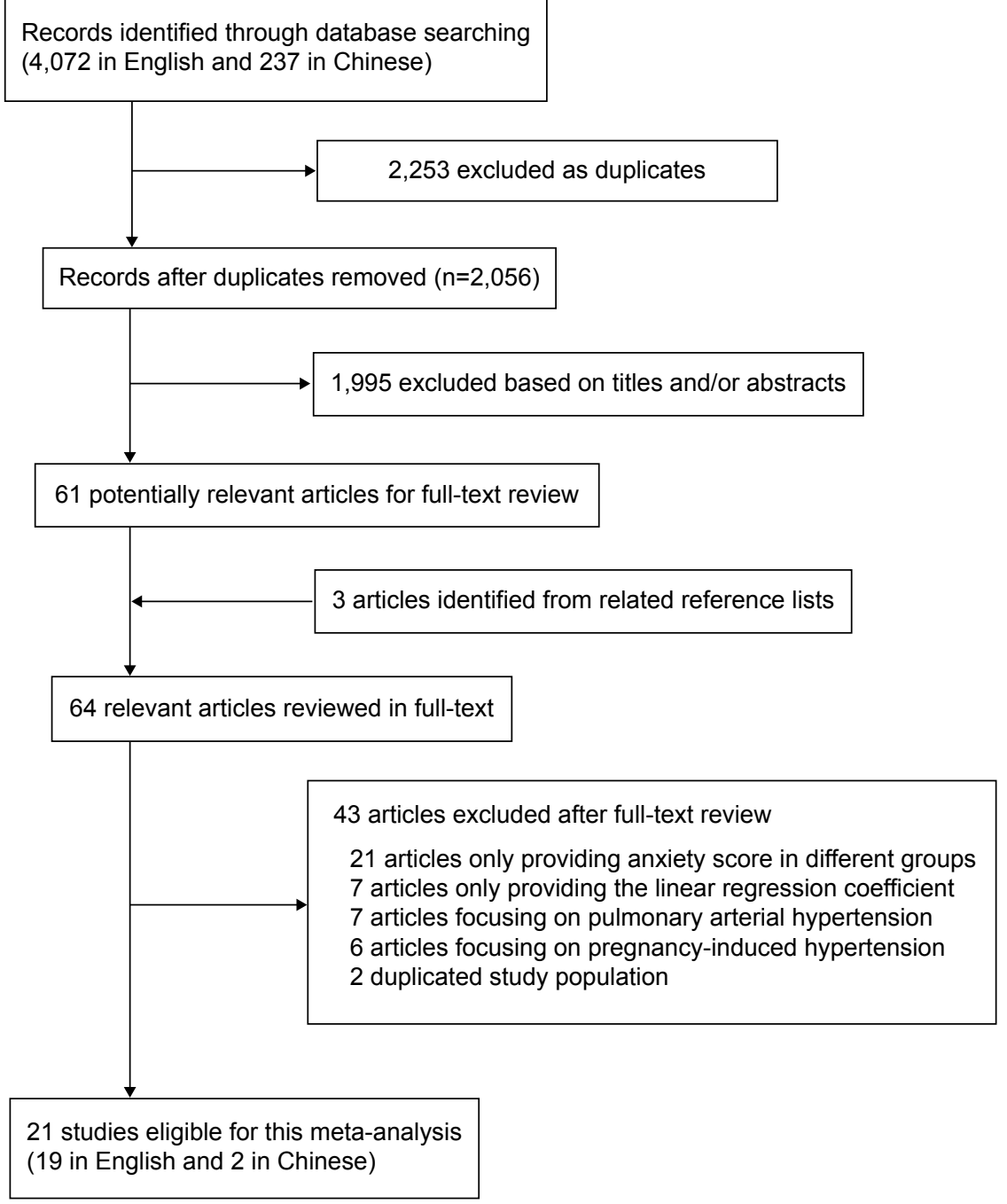

Figure I Flow diagram of studies selection in meta-analysis. 
addition, we searched and identified studies not captured by our database by reviewing the reference lists in retrieved articles.

\section{Inclusion criteria}

Articles were considered for inclusion in the systematic review if: the authors reported data from an original, peerreviewed study (ie, not case reports, comments, letters, meeting abstracts, or review articles); the study was a cross-sectional or prospective study with an adult population (age $\geq 18$ years); the exposure of interest was one or more types of anxiety defined according to standard instruments: and odds ratio (OR), relative risk, or hazard ratio (HR) with $95 \%$ confidence interval ( $\mathrm{CI}$; or data to calculate it) were reported. If multiple articles were published from the same population, the most informative report was included.

\section{Data extraction and quality assessment}

The following data were extracted from each study: the first author's name, year of publication, study site, number of participants, and years of follow-up for prospective studies, participants' characteristics (age range or mean age and sex composition), anxiety measures, analysis strategy (statistical models and covariates adjusted in the models), and results (prevalence, incidence, unadjusted or adjusted OR, and 95\% CI). For some studies providing ORs for different types of anxiety, we used meta-analysis to incorporate these values into one combined OR that presents the association of anxiety with hypertension. The nine-star Newcastle-Ottawa Scale $^{21}$ and eleven-score Agency for Healthcare Research and Quality ${ }^{22}$ were used, respectively, to estimate the quality of prospective studies and cross-sectional studies. Study inclusion, data extraction, and quality assessment were performed by two independent investigators (YP and JY). Any disagreement was settled by discussion among all of the authors.

\section{Statistical analysis}

The research strategy has been described in previous studies. ${ }^{23}$ The pooled measure was calculated as the inverse varianceweighted mean of the logarithm of the OR (HR) with 95\% CI to assess the strength of association between anxiety disorders and risk of hypertension. Heterogeneity among studies was assessed using the $Q$ test and the $I^{2}$ statistic, which describes the proportion of total variation attributable to between-study heterogeneity as opposed to random error or chance. ${ }^{24}$ In the presence of substantial heterogeneity $\left(I^{2}>50 \%\right),{ }^{25}$ the DerSimonian and Laird random effect model (REM) was applied as the pooling method; otherwise, the fixed effect model was adopted. Meta-regression with restricted maximum likelihood estimation was performed to assess the potentially important covariates exerting substantial impact on betweenstudy heterogeneity. The "leave one out" sensitivity analysis ${ }^{26}$ was conducted using $I^{2}>50 \%$ as the criterion to assess the key studies with substantial impact on between-study heterogeneity. An analysis of influence was conducted, ${ }^{27}$ which describes how robust the pooled estimator is to removal of individual studies. An individual study is suspected of excessive influence if the point estimate of its omitted analysis lies outside the $95 \%$ CIs of the combined analysis. Publication bias was estimated using Egger's regression asymmetry test. ${ }^{28}$ All statistical analyses were performed using STATA/SE version 13.1 (Stata Corporation, College Station, TX, USA). All $P$-values were two-sided, and those less than 0.05 were considered to be statistically significant.

\section{Results}

\section{Literature search and study selection}

The study's identified and selected procedures are summarized in Figure 1. Twenty-one studies were finally included in our analysis. Among them, 13 cross-sectional studies ${ }^{11,15,18,20,29-37}$ (two in the USA, five in Europe, three in the People's Republic of China, one in Brazil, one in South Africa, and one worldwide) and eight prospective studies ${ }^{6,12-14,17,38-40}$ (six in the USA and two in Europe) of the association between anxiety and hypertension were included in the analysis. General characteristics in the published articles included in this meta-analysis are shown in Tables 1 and 2. The duration of follow-up ranged from 1 to 25 years for the prospective studies. Stars in Tables 1 and 2 indicate the quality of the study. Among the 13 studies in Table 1, three scored nine stars, five scored eight stars, and five scored seven stars. Among the eight studies in Table 2, one scored nine stars, five scored eight stars, and one scored six stars. The ORs were extracted or calculated from the original articles. Other characteristics, such as age of participants, sample size, and diagnostic criteria for anxiety were also presented in Tables 1 and 2.

\section{Cross-sectional studies of the association between anxiety and hypertension}

Thirteen cross-sectional studies including 151,389 subjects were included in the analysis of the association of anxiety with risk of hypertension. REM was used because substantially significant between-study heterogeneity was observed $\left(P_{\mathrm{Q}}<0.001 ; I^{2}=84.9 \%\right)$. Pooled results showed that anxiety had a significant positive association with hypertension (OR 1.40, 95\% CI 1.20-1.62; Figure 2). Significant publication 


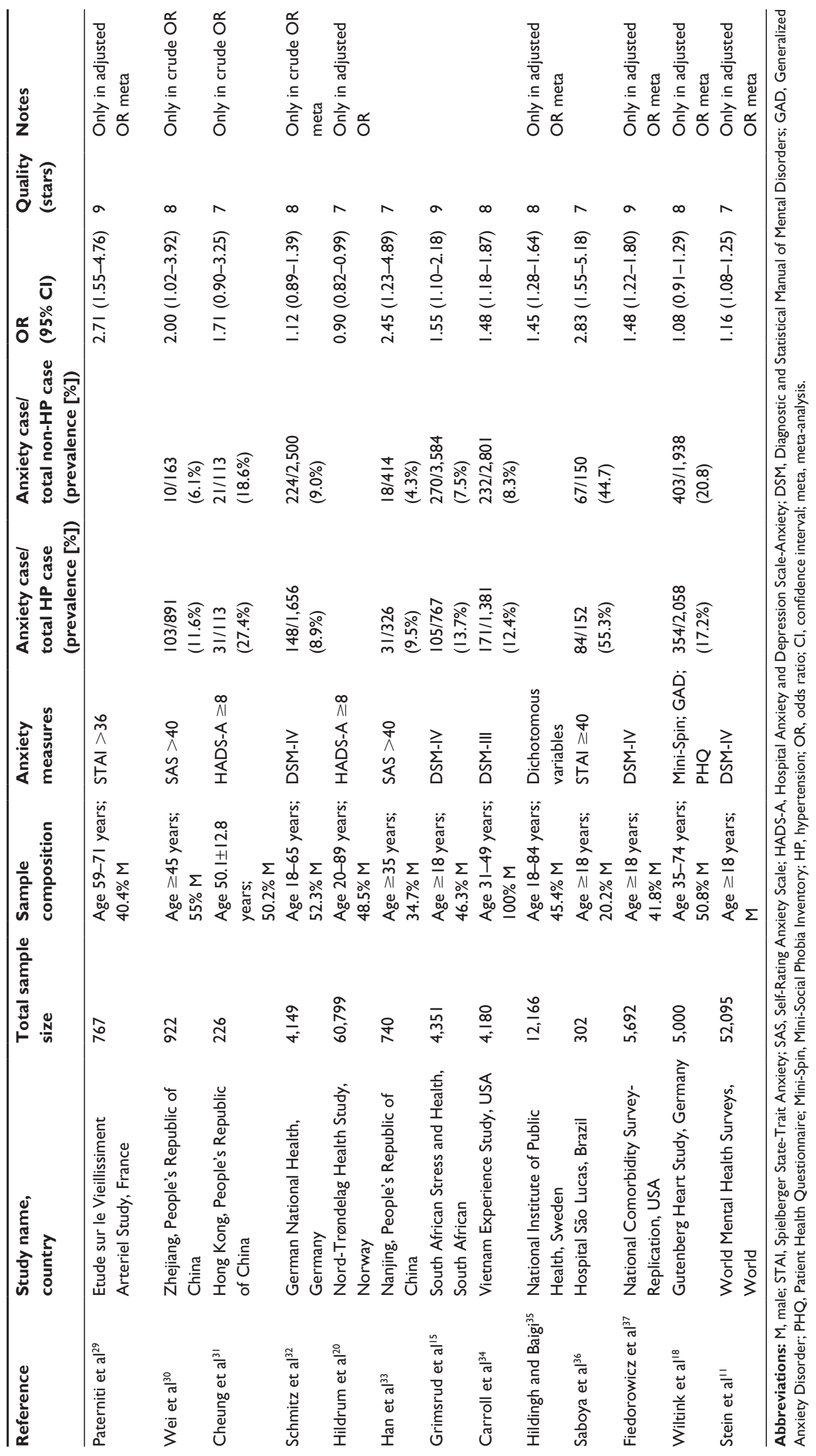




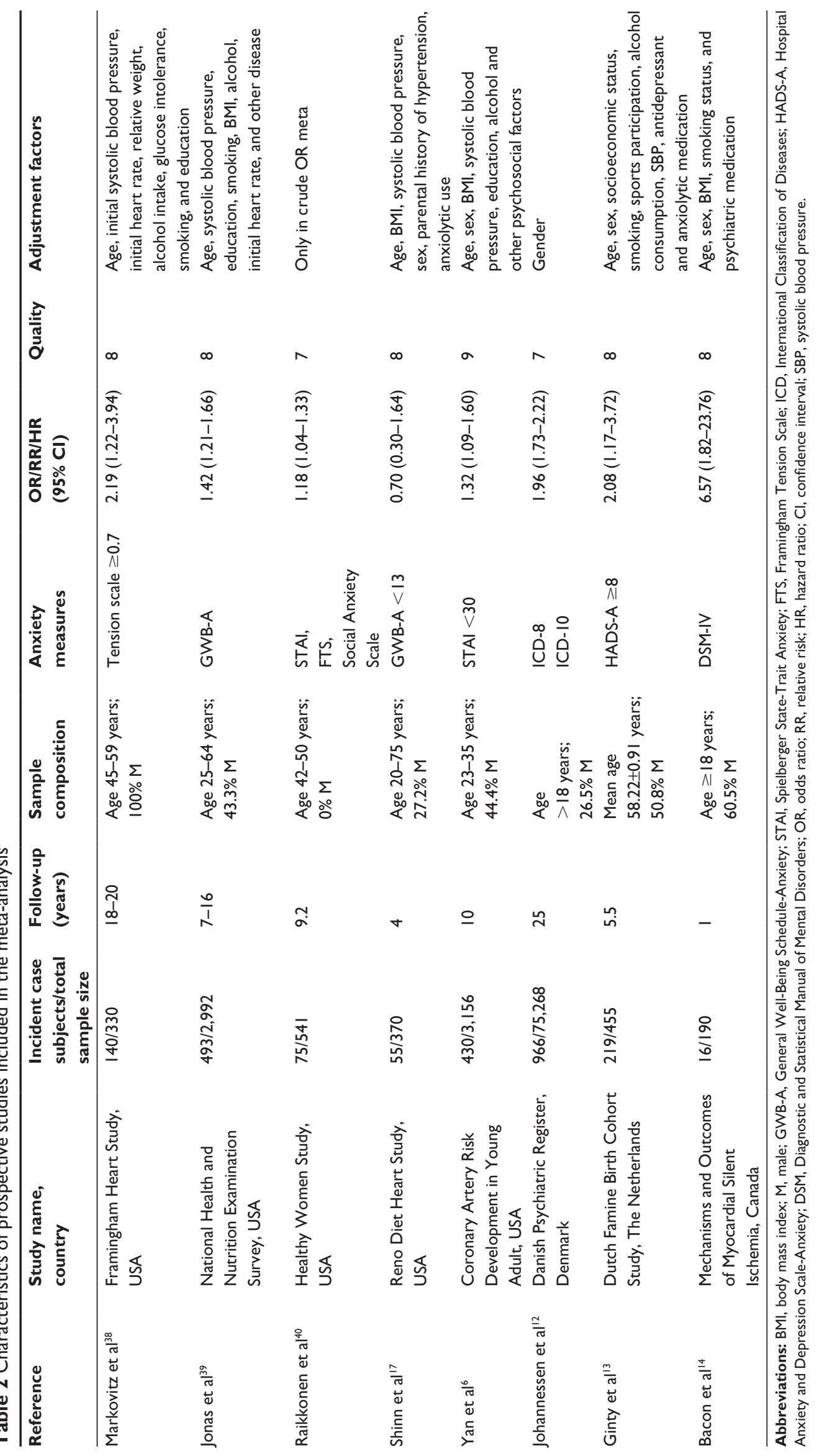




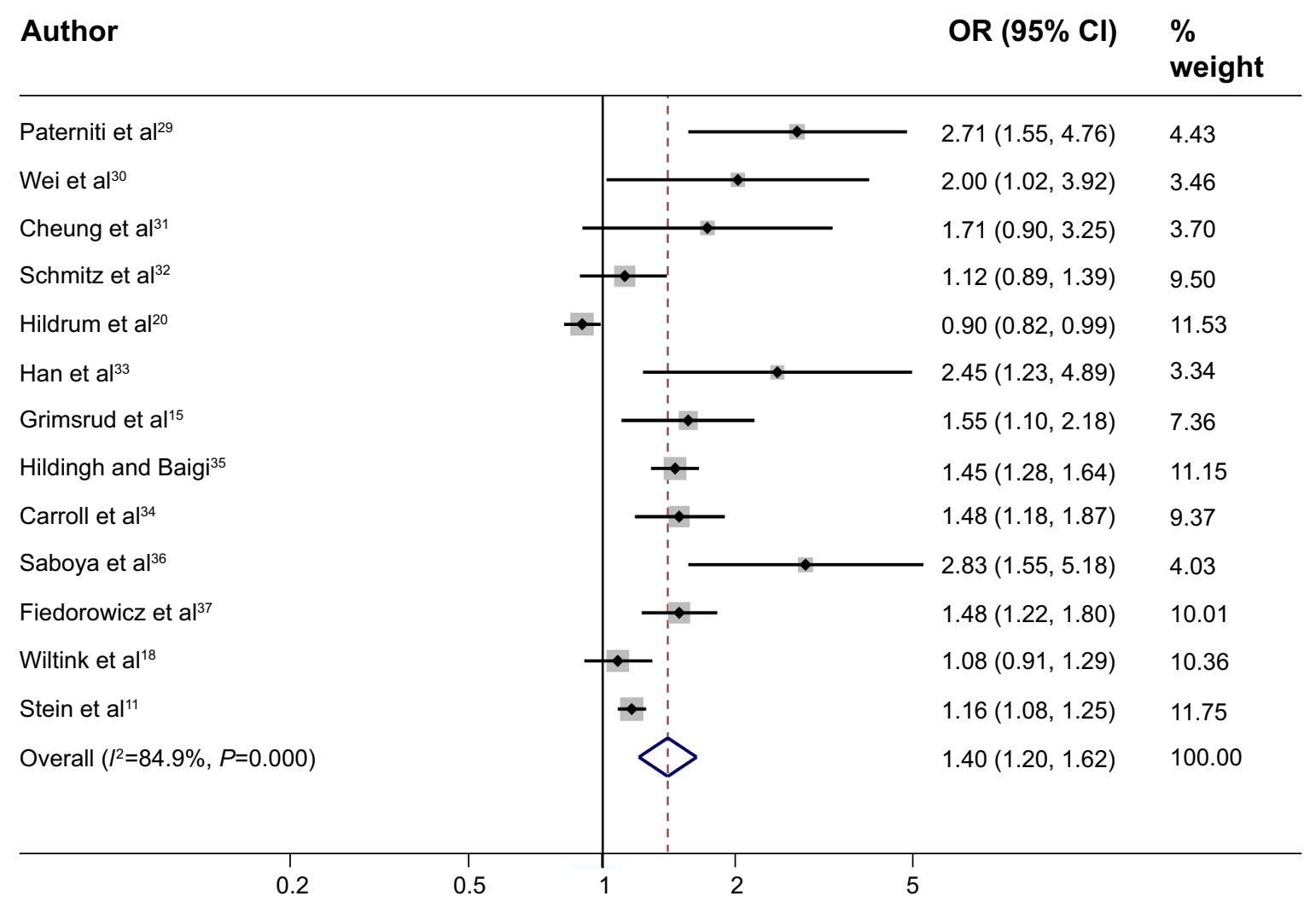

Figure 2 Random effects meta-analysis of cross-sectional studies of the association between anxiety and hypertension (I 3 studies included). Note: Weights are from random effects analysis.

Abbreviations: $\mathrm{OR}$, odds ratio; $\mathrm{Cl}$, confidence interval.

bias was detected $(P=0.016)$. After trim and fill analysis, the final result was still significant (OR 1.18, 95\% CI 1.02-1.37).

\section{Prospective studies of anxiety predicting hypertension risk}

Eight prospective studies investigated the association between the baseline anxiety status and incident hypertension with a total sample size of 80,146 and 2,394 hypertension case subjects. Characteristics of the studies are shown in Table 2. The pooled adjusted HR by REM was 1.55 (95\% CI 1.24-1.94; Figure 3), with strong heterogeneity detected $\left(P_{\mathrm{Q}}<0.001\right.$; $\left.I^{2}=84.6 \%\right)$. No publication bias was detected $(P=0.663)$.

\section{Sources of heterogeneity and sensitivity analysis}

The strong heterogeneities between studies were found in both cross-sectional studies and prospective studies. The univariate meta-regression, with the covariates of location (categorized as American, European, East Asian, and other), diagnostic criteria for anxiety (categorized as structured diagnostic interviews, ie, Diagnostic and Statistical Manual of Mental
Disorders or International Classification of Diseases, and selfreport symptom scales), age (categorized only as middle-aged and other) and sex, sample size, year of publication, quality, and years of follow-up ( $\geq 7$ and $<7$, only for prospective study), showed that none of the aforementioned covariates had a significant impact on between-study heterogeneity.

Subgroup analyses for location, diagnostic criteria for anxiety, age, sex, years of follow-up (only for prospective study) also did not find a source of heterogeneity and indicated that the effects of anxiety in nearly all subgroups were still significant (Table 3).

"Leave one out" sensitivity analysis was performed for the all groups with an $I^{2}>50 \%$, and the pooled results did not change substantially.

\section{Discussion}

To the best of our knowledge, this is the first meta-analysis examining the association between anxiety and hypertension using data from both cross-sectional and prospective studies. We found that anxiety and hypertension were significantly correlated in cross-sectional studies, and a direct association was also observed in prospective studies. 


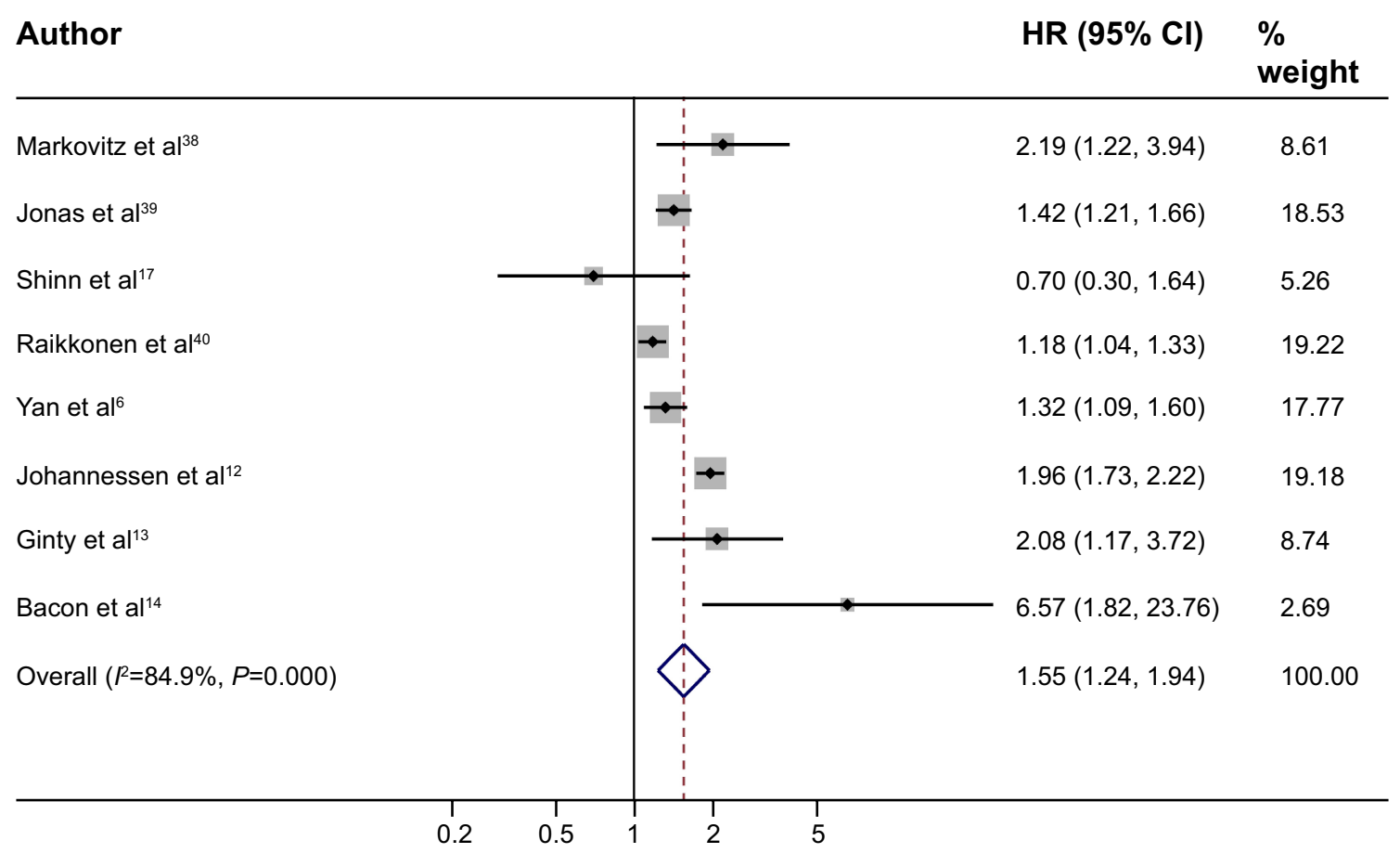

Figure 3 Random effects meta-analysis of prospective studies of the association between anxiety and risk of hypertension (eight studies included). Note: Weights are from random effects analysis.

Abbreviations: $\mathrm{HR}$, hazards ratio; $\mathrm{Cl}$, confidence interval.

Some cross-sectional studies reported a higher anxiety score in participants with hypertension than for those without hypertension. However, the methods used for assessment of anxiety varied significantly in the different studies. Therefore, we could not pool the anxiety scores; instead, we pooled the ORs, a measure of association that was more consistent across studies. Our final pooled OR was 1.18 (95\% CI 1.02-1.37), suggesting that anxiety and hypertension are significantly related. The pooled ORs remained significant in subgroups for location, diagnosis criteria for anxiety, age, and sex. Although strong heterogeneity was found, meta-regression showed that the location, diagnostic criteria for anxiety, age and sex, sample size, year of publication and quality were not the source of between-study heterogeneity.

Table 3 Subgroup analyses to explore source of heterogeneity

\begin{tabular}{|c|c|c|c|c|c|c|}
\hline \multirow[t]{2}{*}{ Subgroups } & \multicolumn{3}{|c|}{ Cross-sectional studies } & \multicolumn{3}{|c|}{ Prospective studies } \\
\hline & $\mathbf{n}$ & $I^{2}(\%)$ & OR $(95 \% \mathrm{Cl})$ & $\mathbf{n}$ & $I^{2}(\%)$ & HR $(95 \% \mathrm{Cl})$ \\
\hline \multicolumn{7}{|l|}{ Location } \\
\hline American & 2 & 0.0 & $1.480(1.276-1.717)$ & 6 & 66.2 & $1.366(1.124-1.660)$ \\
\hline European & 5 & 91.4 & $1.237(0.956-1.601)$ & 2 & 0.0 & $1.965(1.740-2.220)$ \\
\hline East Asian & 3 & 0.0 & $2.014(1.370-2.96 \mid)$ & & & \\
\hline Other & 3 & 81.3 & I.57I (I.032-2.390) & & & \\
\hline \multicolumn{7}{|l|}{ Diagnosis of anxiety } \\
\hline Structured diagnostic interviews & 5 & 62.9 & $1.308(1.138-1.504)$ & 2 & 70.4 & $3.010(0.968-9.355)$ \\
\hline Self-report symptom scales & 8 & 89.3 & $1.575(1.195-2.075)$ & 6 & 55.4 & $1.354(1.153-1.590)$ \\
\hline \multicolumn{7}{|l|}{ Age } \\
\hline Middle-aged & 8 & 78.6 & 1.611 (1.333-1.947) & 5 & 83.5 & $1.543(1.169-2.038)$ \\
\hline Other & 5 & 80.3 & I. I 46 (0.933-I.408) & 3 & 72.7 & $1.632(1.017-2.620)$ \\
\hline \multicolumn{7}{|l|}{ Sex } \\
\hline Male & 4 & 25.7 & $1.410(1.208-1.645)$ & 3 & 75.9 & $2.063(1.395-3.052)$ \\
\hline Female & 3 & 70.9 & $1.533(1.005-2.339)$ & 3 & 88.0 & 1.421 (1.03I-I.957) \\
\hline \multicolumn{7}{|l|}{ Follow-up, years } \\
\hline$<7$ & & & & 3 & 77.5 & $1.945(0.677-5.590)$ \\
\hline$\geq 7$ & & & & 5 & 88.8 & $1.505(1.192-1.900)$ \\
\hline
\end{tabular}

Note: $I^{2}$ indicates heterogeneity.

Abbreviations: $\mathrm{OR}$, odds ratio; $\mathrm{HR}$, hazard ratio; $\mathrm{Cl}$, confidence interval. 
Cross-sectional studies do not provide the temporal relationship between anxiety and hypertension, so we conducted a further meta-analysis to investigate the association between anxiety and hypertension in prospective studies. The pooled adjusted HR by REM was 1.55 (95\% CI 1.24-1.94), indicating that anxiety was an independent risk factor for incident hypertension. This prospective association between anxiety and hypertension was consistent with results from the cross-sectional studies and also in agreement with two recent meta-analyses showing a reciprocal association between anxiety and coronary heart disease ${ }^{41}$ and between anxiety and heart rate variability. ${ }^{42}$ Anxiety and depression are closely linked..$^{43}$ A previous review also shows an increased risk of hypertension in depressed patients and an increased risk of depression in hypertensive patients. ${ }^{44}$ However, a recent meta-analysis in the elderly does not support that view that hypertension is a possible risk factor of depression..$^{45}$ Considering current contradictory results in original articles ${ }^{46}$ a systematic review should be undertaken to explore the relationship between depression and hypertension with the most up-to-date evidence.

The mechanism between anxiety and hypertension is complex. Generally, anxiety increases blood pressure, systemic vascular resistance, sympathetic activity, plasma renin activity, the homeostasis model, and blood lipids. First, anxiety increases blood pressure in the short term, and the white coat effect derived from anxiety is a typical example. ${ }^{47,48}$ A recent ambulatory blood pressure monitoring study reported that anxiety disorder was associated with nocturnal and early morning hypertension in hypertensive outpatients. ${ }^{49}$ Second, anxiety has a close relationship with the renin angiotensin system and increases the level of angiotensin II. ${ }^{50,51}$ Long-term anxiety may decrease vascular variability, so that persistent vascular resistance leads to hypertension. ${ }^{52}$ Third, some experiments show that patients with anxiety usually have physiological signs of sympathetic activation, and anxiety can strongly stimulate sympathetic nervous outflow and the vasovagal reflex. ${ }^{53,54}$ Rozanski et al contend that anxiety can activate the sympathetic nervous system, increase cardiac output, constrict blood vessels, and raise arterial blood pressure. ${ }^{55}$

Moreover, a long-term anxiety state will improve the sympathetic response and more easily activate the sympathetic nervous system. ${ }^{56}$ Activation of the sympathetic nervous system not only reduces renal blood flow, increases renal water and sodium retention, and elevates blood pressure, ${ }^{57}$ but also damages endothelial cells, causes endothelial dysfunction and increasing the risk of atherosclerosis. Sympathetic activation can cause abnormal hemodynamic changes and abnormal lipid metabolism, such as decreasing high-density lipoprotein cholesterol and increasing low-density lipoprotein cholesterol, which affects endothelial function. ${ }^{58}$ In addition, endothelial cells in animals with heightened sympathetic nervous activity present structural changes and greater immunoreactivity. ${ }^{59}$ Fourth, the hypothalamo-pituitary-adrenal axis is the major physiological stress response system in the body. ${ }^{60}$ When this axis is dysfunctional, increasing steroid hormone secretion causes water and sodium retention, leading to high blood pressure.$^{61}$ Further, the indirect association between anxiety and increased risk of hypertension might also derive from the characteristics of anxious subjects, who usually have a more unhealthy lifestyle in general. In other words, they usually have some adverse behaviors, such as increased eating, smoking, and alcohol use, and take less exercise, due to stress and anxiety, that impacts health. ${ }^{62}$

On the other hand, previous studies have also found that patients with hypertension awareness have an increased risk of anxiety disorders. ${ }^{16,32}$ Thus, anxiety and hypertension may interact to affect human health. Moreover, anxiety is one of the barriers in treatment of hypertension. ${ }^{63}$ Khatib et al identify stress, anxiety, and depression as the most common reported barriers hindering or delaying lifestyle modification. ${ }^{64}$ Therefore, conventional antihypertensive therapy with psychological support and antianxiety treatment, such as diazepam, ${ }^{65}$ and metacognitive detached mindfulness therapy and stress management training ${ }^{66}$ could achieve better efficacy in hypertensive patients with anxiety.

This meta-analysis had several strengths. It is the first to explicitly examine the association between anxiety and hypertension on the basis of a comprehensive literature search. This meta-analysis also had a large sample size, which increased the accuracy of the effect estimate. However, the potential limitations of this meta-analysis should be considered. First, it only included English and Chinese language articles; eligible articles published in other languages were not included in this analysis, which may influence the pooled estimated value. Second, because of the inability to obtain raw data, we could perform only a study-level but not a patient-level meta-analysis, which enabled us to adjust for multiple factors. Third, the measurements of anxiety varied among the 21 included studies with regard to different diagnostic instruments, so this might affect the pooled results. We suggest that the DSM-IV should be a preferred instrument to diagnose anxiety disorder in the future because it is the newest standard developed by many experts. Fourth, the outcomes of anxiety and hypertension in our study focused on 
OR, relative risk, and HR, so some studies with other indices, such as a linear regression coefficient, were excluded. Finally, the heterogeneity between studies included in our study should be paid attention to, although some common factors have been considered to detect the source of heterogeneity.

The results of this meta-analysis indicate an association between anxiety and increased risk of hypertension.

\section{Conclusion}

It is important to explore the short-term and long-term effect of anxiety on hypertension. In addition, importance should be attached to the bidirectional association between anxiety and hypertension, especially in the treatment of hypertension. Moreover, the association between anxiety and increased risk of hypertension in this meta-analysis might be confounded by various factors. Therefore, large-scale, randomized controlled trials are recommended to assess the impact of anxiety on incidence rates of hypertension.

\section{Acknowledgment}

The study was supported by the army logistics scientific research funds (AWS13J003), the Psychological Subject of the General Logistics Department (12XLZ211), and the National Science and Technology Support Project (2009BAI77B04).

\section{Disclosure}

All authors declare that they have no competing interests in this work.

\section{References}

1. World Health Organization. Global health risks: mortality and burden of disease attributable to selected major risks. Available from: http://www. who.int/healthinfo/global_burden_disease/GlobalHealthRisks_report_ full.pdf. Accessed January, 192015.

2. Kearney PM, Whelton M, Reynolds K, Muntner P, Whelton PK, He J. Global burden of hypertension: analysis of worldwide data. Lancet. 2005;365(9455):217-223.

3. Fava C, Danese E, Montagnana M, et al. Serine/threonine kinase 39 is a candidate gene for primary hypertension especially in women: results from two cohort studies in Swedes. J Hypertens. 2011;29(3): 484-491.

4. Kowalik M. Psychosomatic aspects of arterial hypertension in women. Ann Univ Mariae Curie Sklodowska Med. 2004;59(1):245-249.

5. Markovitz JH, Jonas BS, Davidson K. Psychologic factors as precursors to hypertension. Curr Hypertens Rep. 2001;3(1):25-32.

6. Yan LL, Liu K, Matthews KA, Daviglus ML, Ferguson TF, Kiefe CI. Psychosocial factors and risk of hypertension: the Coronary Artery Risk Development in Young Adults (CARDIA) study. JAMA. 2003;290(16): 2138-2148.

7. Byrd JB, Brook RD. Anxiety in the "age of hypertension". Curr Hypertens Rep. 2014;16(10):486-486.

8. Reeves WC, Strine TW, Pratt LA, et al. Mental illness surveillance among adults in the United States. MMWR Surveill Summ. 2011; 60 Suppl 3:1-29.
9. McEvoy PM, Grove R, Slade T. Epidemiology of anxiety disorders in the Australian general population: findings of the 2007 Australian National Survey of Mental Health and Wellbeing. Aust NZJ Psychiatry. 2011;45(11):957-967.

10. Mendlowicz MV, Stein MB. Quality of life in individuals with anxiety disorders. Am J Psychiatry. 2000;157(5):669-682.

11. Stein DJ, Aguilar-Gaxiola S, Alonso J, et al. Associations between mental disorders and subsequent onset of hypertension. Gen Hosp Psychiatry. 2014;36(2):142-149.

12. Johannessen L, Strudsholm U, Foldager L, Munk-Jørgensen P. Increased risk of hypertension in patients with bipolar disorder and patients with anxiety compared to background population and patients with schizophrenia. J Affect Disord. 2006;95(1-3):13-17.

13. Ginty AT, Carroll D, Roseboom TJ, Phillips AC, de Rooij SR. Depression and anxiety are associated with a diagnosis of hypertension 5 years later in a cohort of late middle-aged men and women. J Hum Hypertens. 2013;27(3):187-190.

14. Bacon SL, Campbell TS, Arsenault A, Lavoie KL. The impact of mood and anxiety disorders on incident hypertension at one year. Int J Hypertens. 2014;2014:953094.

15. Grimsrud A, Stein DJ, Seedat S, Williams D, Myer L. The association between hypertension and depression and anxiety disorders: results from a nationally-representative sample of South African adults. PLoS One. 2009;4(5):e5552.

16. Hamer M, Batty GD, Stamatakis E, Kivimaki M. Hypertension awareness and psychological distress. Hypertension. 2010;56(3):547-550.

17. Shinn EH, Poston WSC, Kimball KT, St Jeor ST, Foreyt JP. Blood pressure and symptoms of depression and anxiety: a prospective study. Am J Hypertens. 2001;14(7):660-664.

18. Wiltink J, Beutel ME, Till Y, et al. Prevalence of distress, comorbid conditions and well being in the general population. $J$ Affect Disord. 2011;130(3):429-437.

19. Hildrum B, Romild U, Holmen J. Anxiety and depression lowers blood pressure: 22-year follow-up of the population based HUNT study, Norway. BMC Public Health. 2011;11:601.

20. Hildrum B, Mykletun A, Stordal E, Bjelland I, Dahl AA, Holmen J. Association of low blood pressure with anxiety and depression: the Nord-Trondelag Health Study. J Epidemiol Community Health. 2007; 61(1):53-58.

21. Wells GA, Shea B, O'Connell D. The Newcastle-Ottawa Scale (NOS) for assessing the quality of nonrandomised studies in meta-analyses. 2000. Available from: http://www.ohri.ca/programs/clinical_epidemiology/ oxford.asp. Accessed January 19, 2015.

22. Rostom A, Dubé C, Cranney A. Celiac Disease-Appendix D. Quality Assessment Forms. Rockville, MD, USA: Agency for Healthcare Research and Quality; 2004.

23. Pan A, Keum N, Okereke OI, et al. Bidirectional association between depression and metabolic syndrome: a systematic review and meta-analysis of epidemiological studies. Diabetes Care. 2012;35(5):1171-1180.

24. Higgins JP, Thompson SG. Quantifying heterogeneity in a metaanalysis. Stat Med. 2002;21(11):1539-1558.

25. Higgins JP, Thompson SG, Deeks JJ, Altman DG. Measuring inconsistency in meta-analyses. BMJ. 2003;327(7414):557-560.

26. Patsopoulos NA, Evangelou E, Ioannidis JP. Sensitivity of betweenstudy heterogeneity in meta-analysis: proposed metrics and empirical evaluation. Int J Epidemiol. 2008;37(5):1148-1157.

27. Tobias A. Assessing the influence of a single study in the meta-analysis estimate. Stata Technical Bulletin. 1999;47:15-17.

28. Egger M, Davey Smith G, Schneider M, Minder C. Bias in meta-analysis detected by a simple, graphical test. BMJ. 1997;315(7109):629-634.

29. Paterniti S, Alperovitch A, Ducimetiere P, Dealberto MJ, Lepine JP, Bisserbe JC. Anxiety but not depression is associated with elevated blood pressure in a community group of French elderly. Psychosom Med. 1999;61(1):77-83.

30. Wei T, Zeng C, Chen L, Wang S, Li S, Chen Q. [Anxiety or/and depression in patients with hypertension]. Chinese Journal of Hypertension. 2003;6:68-70. Chinese. 
31. Cheung BM, Au T, Chan S, et al. The relationship between hypertension and anxiety or depression in Hong Kong Chinese. Exp Clin Cardiol. 2005;10(1):21-24.

32. Schmitz N, Thefeld W, Kruse J. Mental disorders and hypertension: factors associated with awareness and treatment of hypertension in the general population of Germany. Psychosom Med. 2006;68(2):246-252.

33. Han J, Yin XM, Xu F, Hong X, Liang YQ, Wang ZY. [A case-control study on depression and anxiety in hypertensive patients]. Zhonghua Liu Xing Bing Xue Za Zhi. 2008;29(2):125-127. Chinese.

34. Carroll D, Phillips AC, Gale CR, Batty GD. Generalized anxiety and major depressive disorders, their comorbidity and hypertension in middle-aged men. Psychosom Med. 2010;72(1):16-19.

35. Hildingh $\mathrm{C}, \mathrm{Baigi} \mathrm{A}$. The association among hypertension and reduced psychological well-being, anxiety and sleep disturbances: a population study. Scand J Caring Sci. 2010;24(2):366-371.

36. Saboya PM, Zimmermann PR, Bodanese LC. Association between anxiety or depressive symptoms and arterial hypertension, and their impact on the quality of life. Int J Psychiatry Med. 2010;40(3):307-320.

37. Fiedorowicz JG, He J, Merikangas KR. The association between mood and anxiety disorders with vascular diseases and risk factors in a nationally representative sample. J Psychosom Res. 2011;70(2):145-154.

38. Markovitz JH, Matthews KA, Kannel WB, Cobb JL, D'Agostino RB. Psychological predictors of hypertension in the Framingham Study. Is there tension in hypertension? JAMA. 1993;270(20):2439-2443.

39. Jonas BS, Franks P, Ingram DD. Are symptoms of anxiety and depression risk factors for hypertension? Longitudinal evidence from the National Health and Nutrition Examination Survey I Epidemiologic Follow-up Study. Arch Fam Med. 1997;6(1):43-49.

40. Raikkonen K, Matthews KA, Kuller LH. Trajectory of psychological risk and incident hypertension in middle-aged women. Hypertension. 2001;38(4):798-802.

41. Roest AM, Martens EJ, de Jonge P, Denollet J. Anxiety and risk of incident coronary heart disease: a meta-analysis. $\mathrm{J} \mathrm{Am} \mathrm{Coll} \mathrm{Cardiol.}$ 2010;56(1):38-46.

42. Chalmers JA, Quintana DS, Abbott MJ, Kemp AH. Anxiety disorders are associated with reduced heart rate variability: a meta-analysis. Front Psychiatry. 2014;5:80.

43. Stein DJ, Gureje O. Depression and anxiety in the developing world: is it time to medicalise the suffering? Lancet. 2004;364(9430):233-234.

44. Scalco AZ, Scalco MZ, Azul JB, Lotufo Neto F. Hypertension and depression. Clinics (Sao Paulo). 2005;60(3):241-250.

45. Long J, Duan G, Tian W, et al. Hypertension and risk of depression in the elderly: a meta-analysis of prospective cohort studies. $J$ Hum Hypertens. November 20, 2014. [Epub ahead of print].

46. Licht CM, de Geus EJ, Seldenrijk A, et al. Depression is associated with decreased blood pressure, but antidepressant use increases the risk for hypertension. Hypertension. 2009;53(4):631-638.

47. Spruill TM, Pickering TG, Schwartz JE, et al. The impact of perceived hypertension status on anxiety and the white coat effect. Ann Behav Med. 2007;34(1):1-9.

48. Ogedegbe G, Pickering TG, Clemow L, et al. The misdiagnosis of hypertension: the role of patient anxiety. Arch Intern Med. 2008;168(22): 2459-2465.

49. Kayano H, Koba S, Matsui T, et al. Anxiety disorder is associated with nocturnal and early morning hypertension with or without morning surge ambulatory blood pressure monitoring. Circ J. 2012;76(7):1670-1677.
50. Saavedra JM, Ando H, Armando I, et al. Anti-stress and anti-anxiety effects of centrally acting angiotensin II AT1 receptor antagonists. Regul Pept. 2005;128(3):227-238.

51. Braszko JJ, Kulakowska A, Winnicka MM. Effects of angiotensin II and its receptor antagonists on motor activity and anxiety in rats. J Physiol Pharmacol. 2003;54(2):271-281.

52. Fujino T, Nakagawa N, Yuhki K, et al. Decreased susceptibility to renovascular hypertension in mice lacking the prostaglandin I 2 receptor IP. J Clin Invest. 2004;114(6):805-812.

53. Lambert E, Dawood T, Straznicky N, et al. Association between the sympathetic firing pattern and anxiety level in patients with the metabolic syndrome and elevated blood pressure. J Hypertens. 2010;28(3): 543-550.

54. Bajko Z, Szekeres CC, Kovacs KR, et al. Anxiety, depression and autonomic nervous system dysfunction in hypertension. J Neurol Sci. 2012;317(1-2):112-116.

55. Rozanski A, Blumenthal JA, Kaplan J. Impact of psychological factors on the pathogenesis of cardiovascular disease and implications for therapy. Circulation. 1999;99(16):2192-2217.

56. Narita K, Murata T, Hamada T, et al. Interactions among higher trait anxiety, sympathetic activity, and endothelial function in the elderly. J Psychiatr Res. 2007;41(5):418-427.

57. DiBona GF. The sympathetic nervous system and hypertension: recent developments. Hypertension. 2004;43(2):147-150.

58. Mancia G, Grassi G. The autonomic nervous system and hypertension. Circ Res. 2014;114(11):1804-1814.

59. Harris KF, Matthews KA. Interactions between autonomic nervous system activity and endothelial function: a model for the development of cardiovascular disease. Psychosom Med. 2004;66(2):153-164.

60. Kudielka BM, Wüst S. Human models in acute and chronic stress: assessing determinants of individual hypothalamus-pituitary-adrenal axis activity and reactivity. Stress. 2009;13(1):1-14.

61. Hashimoto K, Makino S, Hirasawa R, et al. Abnormalities in the hypothalamo-pituitary-adrenal axis in spontaneously hypertensive rats during development of hypertension. Endocrinology. 1989;125(3):1161-1167.

62. Bonnet F, Irving K, Terra JL, Nony P, Berthezene F, Moulin P. Anxiety and depression are associated with unhealthy lifestyle in patients at risk of cardiovascular disease. Atherosclerosis. 2005;178(2):339-344.

63. Bautista LE, Vera-Cala LM, Colombo C, Smith P. Symptoms of depression and anxiety and adherence to antihypertensive medication. Am J Hypertens. 2012;25(4):505-511.

64. Khatib R, Schwalm JD, Yusuf S, et al. Patient and healthcare provider barriers to hypertension awareness, treatment and follow up: a systematic review and meta-analysis of qualitative and quantitative studies. PLoS One. 2014;9(1):e84238.

65. Grossman E, Nadler M, Sharabi Y, Thaler M, Shachar A, Shamiss A. Antianxiety treatment in patients with excessive hypertension. Am J Hypertens. 2005;18(9 Pt 1):1174-1177.

66. Ahmadpanah M, Paghale SJ, Bakhtyari A, et al. Effects of psychotherapy in combination with pharmacotherapy, when compared to pharmacotherapy only on blood pressure, depression, and anxiety in female patients with hypertension. J Health Psychol. October 7, 2014. [Epub ahead of print].
Neuropsychiatric Disease and Treatment

\section{Publish your work in this journal}

Neuropsychiatric Disease and Treatment is an international, peerreviewed journal of clinical therapeutics and pharmacology focusing on concise rapid reporting of clinical or pre-clinical studies on a range of neuropsychiatric and neurological disorders. This journal is indexed on PubMed Central, the 'PsycINFO' database and CAS,

\section{Dovepress}

and is the official journal of The International Neuropsychiatric Association (INA). The manuscript management system is completely online and includes a very quick and fair peer-review system, which is all easy to use. Visit http://www.dovepress.com/testimonials.php to read real quotes from published authors. 